OPEN ACCESS

Edited by:

Jinbu Li,

China University of Petroleum (East

China), China

Reviewed by:

Bo Liu,

Northeast Petroleum University, China

Zhiye Gao,

China University of Petroleum, China

*Correspondence:

Zhentao Dong

dzt5020@qq.com

Specialty section:

This article was submitted to

Economic Geology,

a section of the journal

Frontiers in Earth Science

Received: 06 July 2021 Accepted: 07 September 2021 Published: 29 September 2021

Citation:

Xue H, Dong Z, Tian S, Lu S, An C,

Zhou Y, Li B and Xin X (2021)

Characteristics of Shale Wettability by

Contact Angle and Its Influencing

Factors: A Case Study in Songliao.

Front. Earth Sci. 9:736938.

doi: 10.3389/feart.2021.736938

\section{Characteristics of Shale Wettability by Contact Angle and Its Influencing Factors: A Case Study in Songliao}

\author{
Haitao Xue ${ }^{1}$, Zhentao Dong ${ }^{1 *}$, Shansi Tian ${ }^{2}$, Shuangfang $\mathrm{Lu}^{1}$, Ce An ${ }^{1}$, Yuan Zhou ${ }^{1}$, \\ Boheng $\mathrm{Li}^{1}$ and Xiaoyi Xin ${ }^{3}$
}

${ }^{1}$ School of Geosciences, China University of Petroleum (East China), Qingdao, China, ${ }^{2}$ Key Laboratory of Continental Shale Hydrocarbon Accumulation and Efficient Development (Northeast Petroleum University), Ministry of Education, Northeast Petroleum University, Daqing, China, ${ }^{3}$ School of Art and Media, Xian Technological University, Xian, China

Wettability is a significant factor in the exploration and development of shale oil. Currently, shale wettability has yet to reach a unified understanding. The contact angle is widely used in the study of shale wettability. However, the pre-treatment of the shale profoundly affects the contact angle. In this paper, the contact angle errors introduced by the pre-treatment of samples are discussed. Shale wettability is influenced by many factors, and there is not yet a systematic study of its influencing factors. Based on the above issues, the shale of the northern Songliao Basin was taken as the subject. The wettability of the different lithofacies is characterized by an improved contact angle method. The compositional characteristics of the shales and oil in the study area were analyzed. Fresh minerals, a single component of oil, and different temperature/pressure conditions were set up to investigate the influencing factors of shale wettability. The studies show that Organic matter abundance and thermal maturity have a positive correlation with oil-wet. Siliceous minerals are positively correlated with water-wet. Carbonate and clay minerals are negatively correlated with water-wet. The mineralogical composition of the shale, the composition of the oil, the characteristics of the aqueous media, the asphaltene deposits on the surface, temperature, and pressure all impact wettability. The affinity of minerals for hydrocarbons is iron minerals > carbonate minerals > clay minerals > siliceous minerals. Minerals are more hydrophilic at low salinity conditions. The deposition of non-hydrocarbons and asphaltenes renders the surface oleophilic. Increasing temperatures will reduce the hydrophilicity of the "oil-water-rock".

Keywords: wettability, shale oil, contact angle, Northern Songliao basin, liquid-liquid extraction

\section{INTRODUCTION}

Shale wettability is the tendency for oil to expand or adhere to the pore surface (Roshan et al., 2016). It is one of the most significant properties of the surface characteristics of shale reservoirs (Alvarez et al., 2016a). Wettability controls the process of shale oil enrichment (Yong et al., 2016; Liu et al., 2018; Song et al., 2020; Liu et al., 2021). The process of enrichment of shale oil can be divided into two processes. Firstly, the oil is enriched within the internal pore network of the organic matter (OM) (Athy et al., 1930). Once the shale oil has met the retention capacity of the OM, it flows out of the OM pores and into the inorganic mineral pores, where it is enriched (Loucks et al., 2014; Liu et al., 2021). Before the oil enters the inorganic pores from the OM pore network, it is hydrophilic due to the film of water on the surface of the inorganic minerals ( $\mathrm{Li}$ et al., 2017). The capillary forces are the resistance as the shale oil 
moves from the OM pores into the inorganic minerals pores. After the oil enters the inorganic mineral pores, the polar compounds in the crude oil will break the water film on the mineral surface, replacing the water molecules adsorbed on the mineral surface (Buckley et al., 2001). Then, the surface absorption by oil will change from hydrophilic to lipophilic (Drummond et al., 2004). This reduces the capillary resistance of oil entering the inorganic minerals pores, making it easier to enrich. Wettability determines the lower limit and type of pore throat for oil filling. In the field of shale oil development, regulating reservoir wettability is key to improving shale oil recovery (Marsden et al., 1965; Ehrlich et al., 1974; Alvarez et al., 2016b; Jia et al., 2021). Wettability is important for selecting the appropriate fracturing fluid to minimize fracturing fluid losses. It is generally accepted that the highest crude oil recovery is achieved under low oil-water interfacial tension and weak water-wetting conditions during water displacement $(\mathrm{He}$ et al., 2018; Li et al., 2021; He et al., 2022).

The surface of shale pore throats is composed of very complex minerals and organic matter, and this composition makes the surface both oil-wet and water-wet (Yang et al., 2019). Generally, shale pores can be divided into relatively large micropores and smaller nanopores (Barnett et al., 2012; Chalmers et al., 2012). Micropores are predominantly found in inorganic minerals, while nanopores are mainly found in organic matter and clay minerals. Inorganic pores are widely considered to be hydrophilic. In contrast, organic pores are considered lipophilic and become more lipophilic as the maturity of the organic matter increases (Begum et al., 2019). The simultaneous presence of inorganic water-wet macropores and organic oil-wet micropores makes the shale double-wetting, distinguishing the shale wettability from conventional reservoirs (Tao Zhang et al., 2018).

Nowadays, shale wettability is characterized by five main methods viz. contact angle method (Siddiqui et al., 2018) (CA), spontaneous imbibition (Li et al., 2019) (SI), zeta potential method (Hoxha et al., 2016), nuclear magnetic resonance (NMR) (Chen et al., 2006), atomic force microscopy (AFM) (Kumar et al., 2005), and molecular dynamics simulation (MD) (Xue et al., 2021). The CA method is convenient, with a test range from strong water-wet to strong oil-wet, and has clear mechanical and thermodynamic significance, satisfying qualitative and quantitative studies and suitable for mechanistic studies. Therefore, CA is widely used in the study of shale wettability (Siddiqui et al., 2018). CA is mainly divided into the sessile drop method, which is used to express the wettability of the "gas-flow-rock system," and the captive bubble drop method, which represents the wettability of the "liquid-liquid-solid" system (Pan et al., 2020). However, numerous factors influence the contact angle. The pre-treatment process of shale samples (organic contamination of the surface and roughness) can severely impact the results. Therefore, the errors introduced by the pre-treatment of shale samples need to be analyzed.

The factors influencing the wettability of shale oil reservoirs can be summarized in the following five aspects: 1) Mineral and shale oil composition (Borysenko et al., 2009; Lu et al., 2019). 2) Water medium characteristics (Agbalaka et al., 2009; Berg et al., 2010). Brine concentration and $\mathrm{pH}$ control the wettability by influencing mineral surface chemistry and oil-water interfacial tension; DLVO theory can describe the interaction between the rock surface/brine and oil/brine interfaces, where "oil-water- rock" wettability depends on the balance between the two forces of electrostatic repulsion and van der Waals forces. 3) pore throat scale (Yu et al., 1986). The smaller the droplet scale, the greater the effect of the upper line tension on the three-phase circumference and the more significant the change in contact angle. 4) Pore throat surface physicochemical properties (Nakae et al., 1998). Cassie (1944) found that the greater the roughness of a solid surface, the more hydrophilic the surface would be. Whereas the surface of reservoir rocks is not smooth and flat, its surface roughness affects wettability. Asphaltenes in shale oil can break the water film on the surface of inorganic minerals in shale and adsorb to its surface, causing changes in wettability 5) Temperature and pressure conditions (Zhang et al., 2018). Changes in temperature and pressure conditions can affect water-rock, oil-rock, oil-water, and oil-water interfacial tensions, thus affecting the wettability of the "oil-water-rock" system. Current research on the factors influencing wettability is scattered, and no systematic studies have been carried out.

Based on the above issues, Qingshankou $\left(\boldsymbol{K}_{2} \boldsymbol{q} \boldsymbol{n}\right)$ and Nenjiang $\left(\boldsymbol{K}_{2} \boldsymbol{n}\right)$ in the northern Songliao Basin were taken as the subjects. The wettability of the different lithofacies is characterized by an improved contact angle method. The compositional characteristics of the shales and oil in the study area were analyzed. Fresh minerals, single components of oil, and different temperature/pressure conditions were set up to investigate the factors influencing the wettability of the shale oil reservoirs.

\section{GEOLOGICAL BACKGROUND AND SAMPLES}

\section{Geological Background of the Study Area}

The target area of this study is the northern Songliao Basin (Figure 1). The Late Cretaceous is a deep and semi-deep lacustrine facies formation developed in the depressional stage of the basin, which is the main source rock and an important shale oil layer in the northern Songliao Basin. The target formations studied are the Qingshankou $\left(\boldsymbol{K}_{2} \boldsymbol{q n}\right)$ and the Nengjiang $\left(\boldsymbol{K}_{2} \boldsymbol{n}\right)$. The thickness of the $\boldsymbol{K}_{2} \boldsymbol{q} \boldsymbol{n}$ is usually in the range of $200-500 \mathrm{~m}$, and the primary lithology is black-brown mud shale interbedded with a small amount of oil shale, and its lithology and petrography are highly variable. The stratigraphy of the $\boldsymbol{K}_{2} \boldsymbol{n}$ is generally in the range of $100-450 \mathrm{~m}$ in thickness, with the lower part of it being sandstone transformed into mudstone and oil shale deposits and the upper part being interbedded with purple-red and green mudstone deposits (Hou et al., 2000; Bechtel et al., 2012; Jia et al., 2013).

\section{Samples Information}

Shales were taken from vital exploratory wells in the Qijia-Gulong Depression, the southern Daqing Changyuan area, and the Sanzhao Depression. Forty-six samples were selected for rock pyrolysis and whole-rock X-ray diffraction analysis (Supplementary Table S1). Then 33 of the samples were chosen for contact angle and liquid-liquid extraction experiments.

Samples from $\boldsymbol{K}_{2} \boldsymbol{q} \boldsymbol{n}$ are all shale with high maturity and high organic matter abundance. In contrast, samples from the $\boldsymbol{K}_{\mathbf{2}} \boldsymbol{n}$ had 

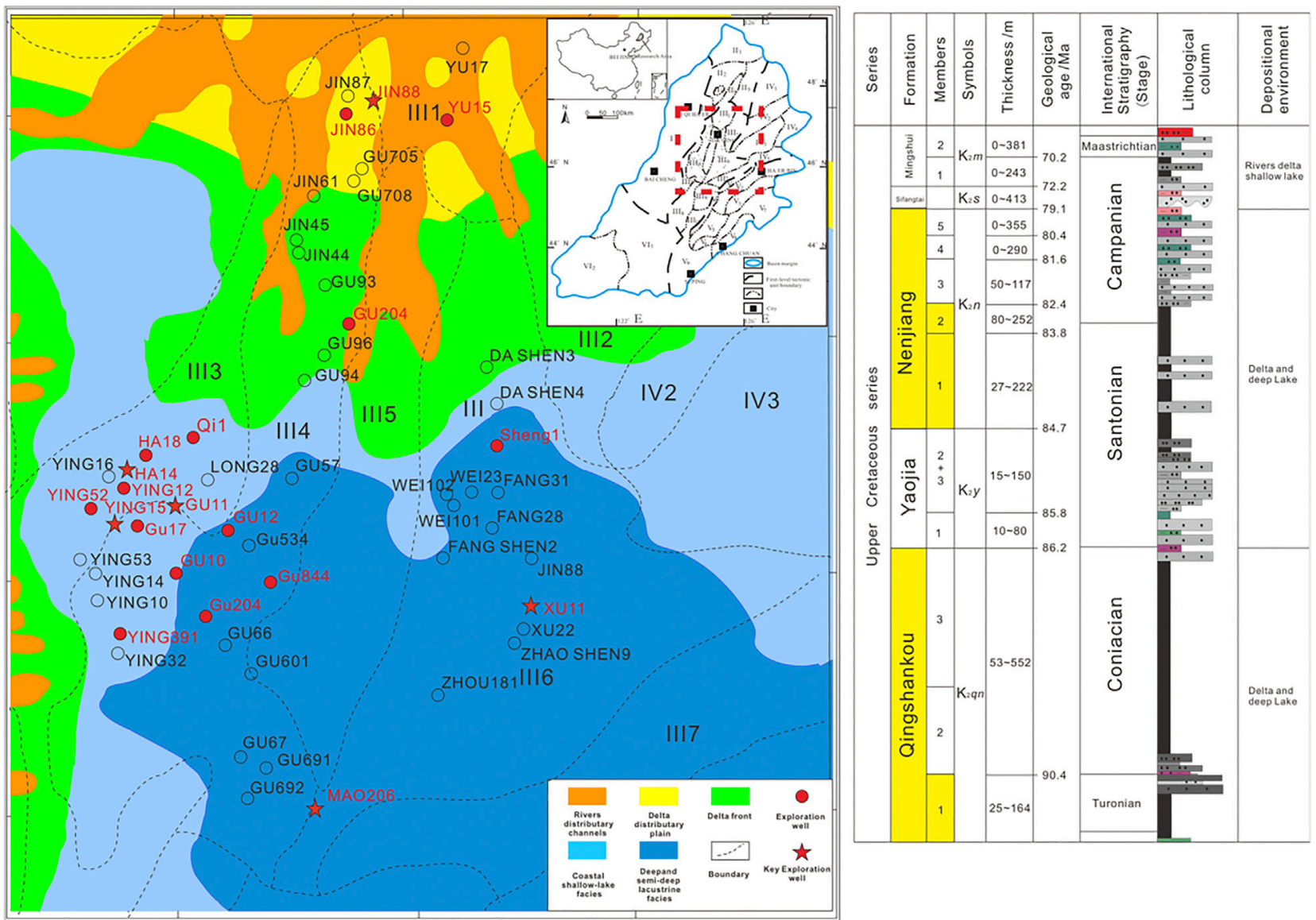

FIGURE 1 | The sedimentary facies of the Qingshankou and Nenjiang Formation (left) and synthetic histogram of the northern Songliao Basin (right). Strata are filled with yellow to represent the study object.

lower maturity and organic matter abundance (Supplementary Table S1).

Figure 2 illustrates the mineralogical composition of the samples. The main minerals that make up the samples are quartz, plagioclase, calcite, dolomite, pyrite, siderite, illite, and kaolinite. The minerals were classified according to their elemental composition and similarity in the crystal structure (Figure 2C) as siliceous minerals (quartz and feldspar), clay minerals (kaolinite and illite), carbonate minerals (calcite and iron dolomite), and iron minerals (pyrite and siderite).

The $\boldsymbol{K}_{\mathbf{2}} \boldsymbol{n}$ (Figure 2B) has a higher siliceous mineral content than the $\boldsymbol{K}_{2} \boldsymbol{q} \boldsymbol{n}$ (Figure 2A), with an average value of $63.7 \%$. The content of clay minerals is lower than that of the $\boldsymbol{K}_{2} \boldsymbol{q} \boldsymbol{n}$, with the percentage of content distributed between 13.5 and $44.3 \%$ and the mean value of $27.82 \%$. The carbonate and iron mineral content is similarly distributed at a lower level.

Referring to the delineation scheme of Liu (Liu et al., 2019) for the shales of the Qingshankou Formation in the southern Songliao Basin, the lithofacies were delineated in terms of the macrostructure (Figure 3), TOC, and mineral composition of the samples. Lu (Shuangfang et al., 2012) proposed a "trichotomous method" for shale oil resource evaluation, in which a TOC of $1 \mathrm{wt}$
$\%$ and $2 \mathrm{wt} \%$ is the threshold for classifying high and low organic matter. In this paper, the samples are divided into high organic matter (TOC $\geq 2 \mathrm{wt} \%$ ), medium organic matter $(1 \mathrm{wt} \% \leq \mathrm{TOC}<$ $2 \mathrm{wt} \%)$, and low organic matter (TOC < $1 \mathrm{wt} \%$ ).

\section{EXPERIMENTAL METHODS}

\section{Experimental Materials}

Fresh minerals were selected concerning the mineral composition of the shale: quartz, plagioclase, calcite, iron dolomite, pyrite, rhodochrosite, illite, and kaolinite. Wettability characterization of single and pure minerals is fundamental to explore the effect of different mineral compositions on the overall wettability of shale. Whole-rock X-ray diffraction analysis of the fresh minerals showed that the purity of the minerals was essentially greater than $97 \%$.

Regarding the shale oil composition, several common compounds were selected for this study, respectively: n-hexane, n-dodecane, and n-octadecane for the saturated hydrocarbon component; benzene for the aromatic component; and 3-dodecylthiophene and $\mathrm{N}, \mathrm{N}$-dimethyldodecylamine for the non-hydrocarbon 

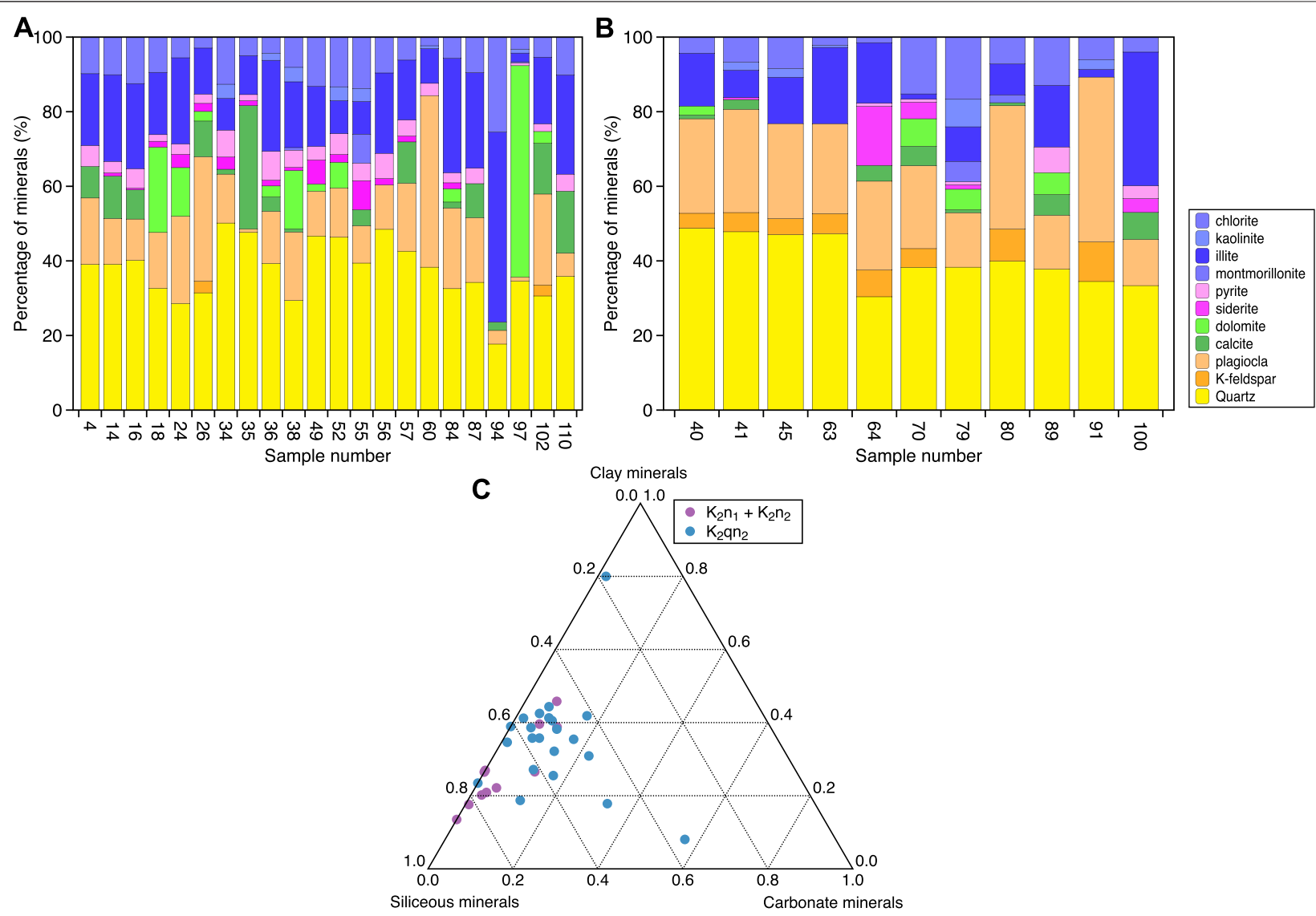

FIGURE 2 | Mineral composition of shale oil reservoirs. (A) Qingshankou shale Oil Reservoir, (B) Nenjiang shale Oil Reservoir, (C) Distribution characteristics of mineral groups.

component. The compounds purchased were Dr. Germany brand products, whose chemical parameters and specifications are shown in Supplementary Table S2. Crude oil samples and kerosene were also used in the experiments. Kerosene was used to represent the low carbon number mixture of hydrocarbons in crude oil, whose main components are alkanes of $n-C_{12} \sim n-C_{14}$ and contain small amounts of aromatic hydrocarbons, unsaturated hydrocarbons, cyclic hydrocarbons, and other impurities such as sulfides and gums.

\section{Liquid-Liquid Extraction}

Liquid-Liquid Extraction (LLE) qualitatively evaluates the affinity of shale particles for two liquid phases (Supplementary Figure S1). Samples were crushed to 160 mesh to reduce the effect of buoyancy on results. $0.6 \mathrm{~g}$ of rock powder, water, and kerosene is mixed together, stirred thoroughly and shaken for $5 \mathrm{~min}$, and then left for a while. Different particles have different hydrophilic or oleophilic properties on the surface, which determines whether they sink in water or are suspended in the oil phase. The distribution of the particles is used to qualitatively determine the affinity of the rock particles for water or oil.

\section{Pre-treatment of Samples for Contact Angle}

It was not known what the ideal level of polishing required for the sample was. To solve this problem, uartz and calcite chips were polished separately using different grit sizes $(80,160,400,1,200$, $2,000,6,000,8,000,10,000$ grit and mirror polish). The "oil-waterrock" contact angle of calcite with different roughness was compared to determine the grinding method required for this study surface.

The roughness of a surface can be expressed in terms of $\boldsymbol{R}_{\boldsymbol{a}}$, which is the arithmetic mean of the absolute values of the distances from the points on the measured profile to the reference line within the sampling length $\boldsymbol{L}$. The roughness $\boldsymbol{R}_{\boldsymbol{a}}$ of different surfaces was measured using the stylus method with a Hommel-Etamic T8000 roughness profiler from Suzhou Winters Measurement Technology Co.

As shown in Figure $\mathbf{4 A}$, as the grit of the sandpaper is increased, the Ra value decreases, which means a smoother surface. The mirror-polished surface has a meager Ra value of only $20 \mathrm{~nm}$, so the surface can be considered smooth. The contact angle results for different roughness are shown in Figure 4B. As predicted by the Cassie-Baxter model, the contact angle decreases to a specific value and then remains constant as the surface roughness decreases. For highly rough surfaces $(\mathrm{Ra}>0.8 \mu \mathrm{m})$, the contact angle is 

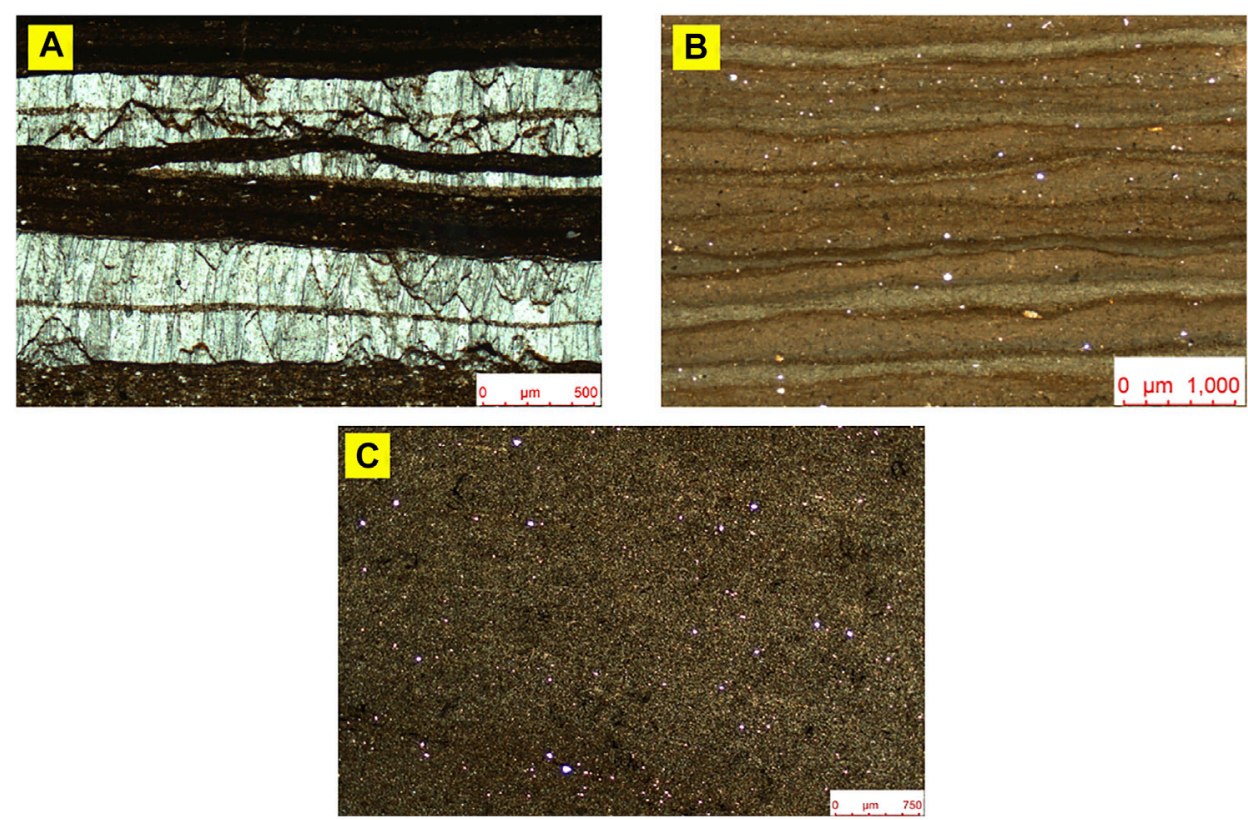

FIGURE 3 | Structural characteristics of shale oil reservoir samples. (A) Bedded structure, sample \#97; (B) Laminar structure, sample \#110; (C) Massive structure, sample \#60.
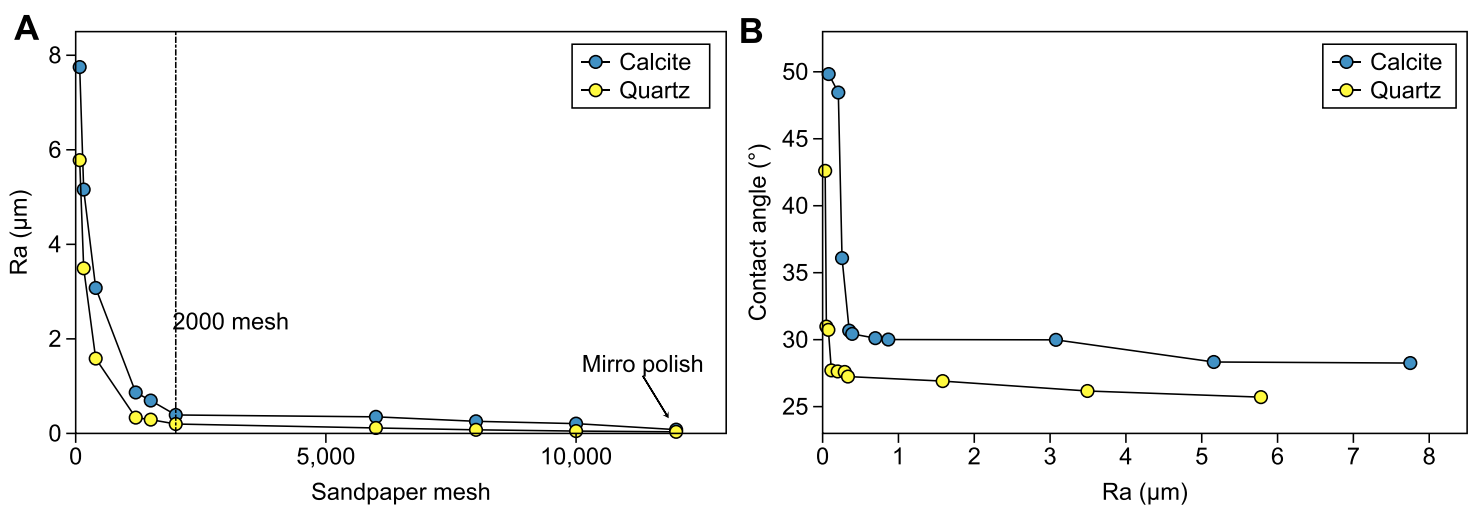

FIGURE 4 | Roughness and contact angle after polishing with different meshes of sandpaper. (A) Sandpaper mesh vs. $R_{a}$, (B) $R_{a}$ vs. contact angle.

almost constant but considerably different from Young's contact angle. However, for relatively smooth surfaces ( $\mathrm{Ra}$ $<0.8 \mu \mathrm{m})$, the contact angle varies significantly. Therefore, there is a solid need to mirror polish the surfaces.

\section{Contact Angle Experiments} "Oil-Water Rock" Contact Angle Prediction Model for Shale

The "oil-water-rock" contact angle (Figure 5B) from the captive bubble method appears to be more consistent with geological conditions than the sessile drop method (Figure 5A). However, when the "oil-water-rock" contact angle of shale is measured using the captive bubble drop method, some samples are found to break up due to the high clay content when immersed in water. Some samples have a very stable water film on the surface, making it difficult for oil droplets to reach the shale surface (Figures 5C,D). Such samples cannot be subjected to the captive bubble method.

Comparison of the "gas-water-rock" and "gas-oil-rock" contact angles for the sessile drop method does not allow for a determination of whether the test sample is more hydrophilic or more lipophilic. To illustrate this point, separate "gas-water-rock" (Figure 6B), "gas-oil-rock" (Figure 6A), and "oil-water-rock" (Figures 6C,D) contact angle experiments were carried out to compare the oil-wetness and water-wetness of quartz surfaces (Figure 6). The results of the "gas-oil-rock" experiment showed that the contact angle of hexane on the quartz surface was $0^{\circ}$ and 
A

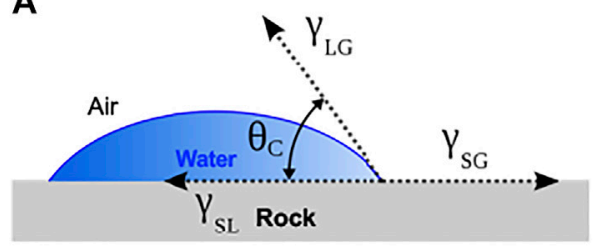

C

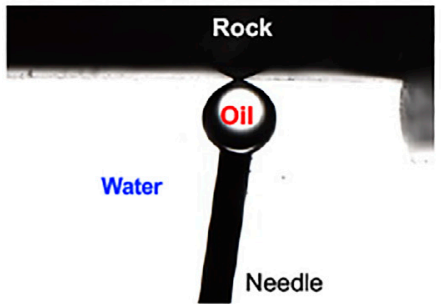

B

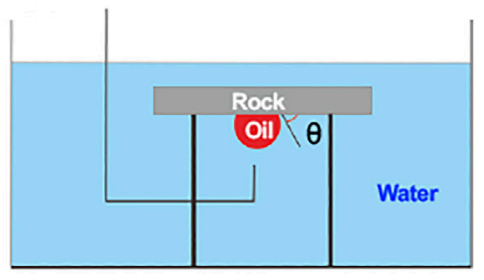

D

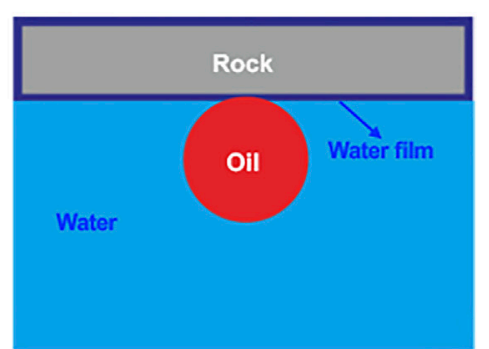

FIGURE 5 | (A) Schematic of sessile drop methods for contact angle measurements; (B) captive bubble methods; (C,D) illustrating the failure of oil droplets to contact the shale surface due to the water film.

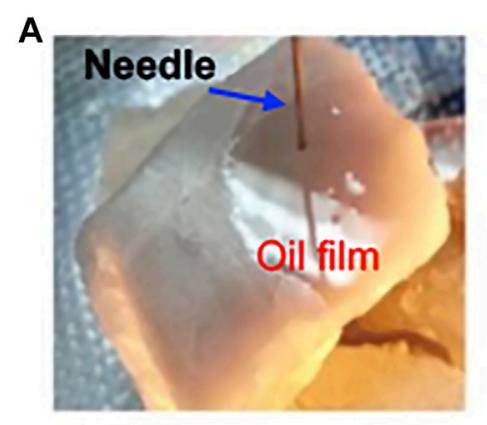

B

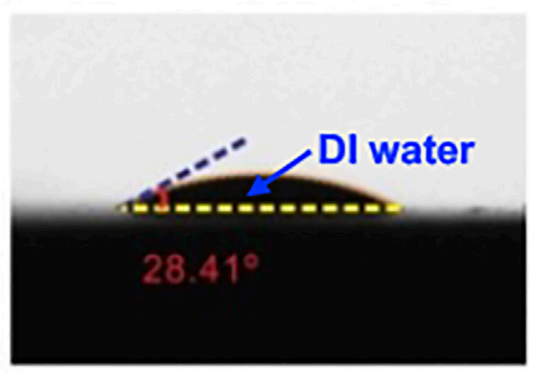

C

D

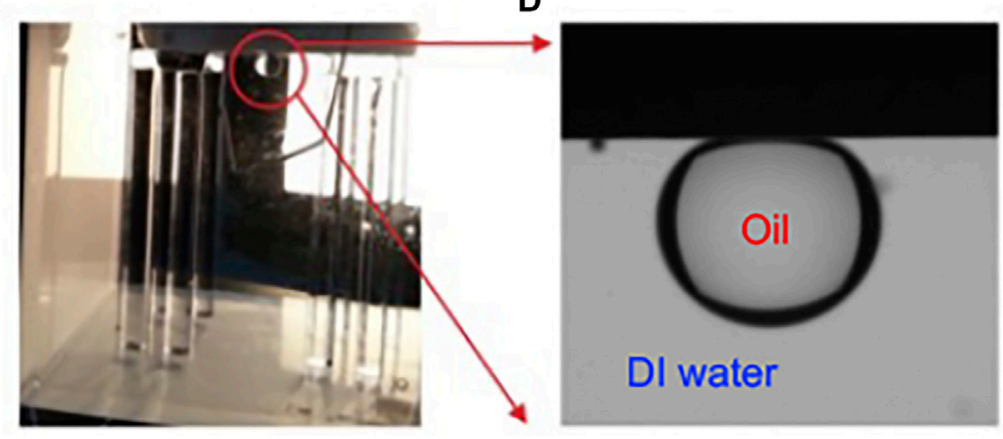

FIGURE 6 | (A) Spreading phenomenon of oil on the quartz surface, (B) Contact angle of DI water on the quartz surface, (C,D) illustrating the hydrophilic nature of quartz.

the quartz was completely oil-wet; the contact angle of DI water on the quartz surface was $28.41^{\circ}$, and the quartz was not completely water-wet. From the experimental assessment of the relative lipophilicity and hydrophilicity of the quartz surface by the sessile drop method, it can be concluded that the surface of quartz is lipophilic. However, the results of the "oilwater-rock" experiments by the captive bubble method show an oil contact angle of $157^{\circ}$ compared to a water contact angle of $23^{\circ}$. Quartz is hydrophilic. This contradicts the conclusions obtained by the sessile drop method. It is clear that the results of the suspended-drop method are accurate for an oil-water environment and that the seated-drop method is not sufficient to determine whether the surface is more lipophilic or hydrophilic. 

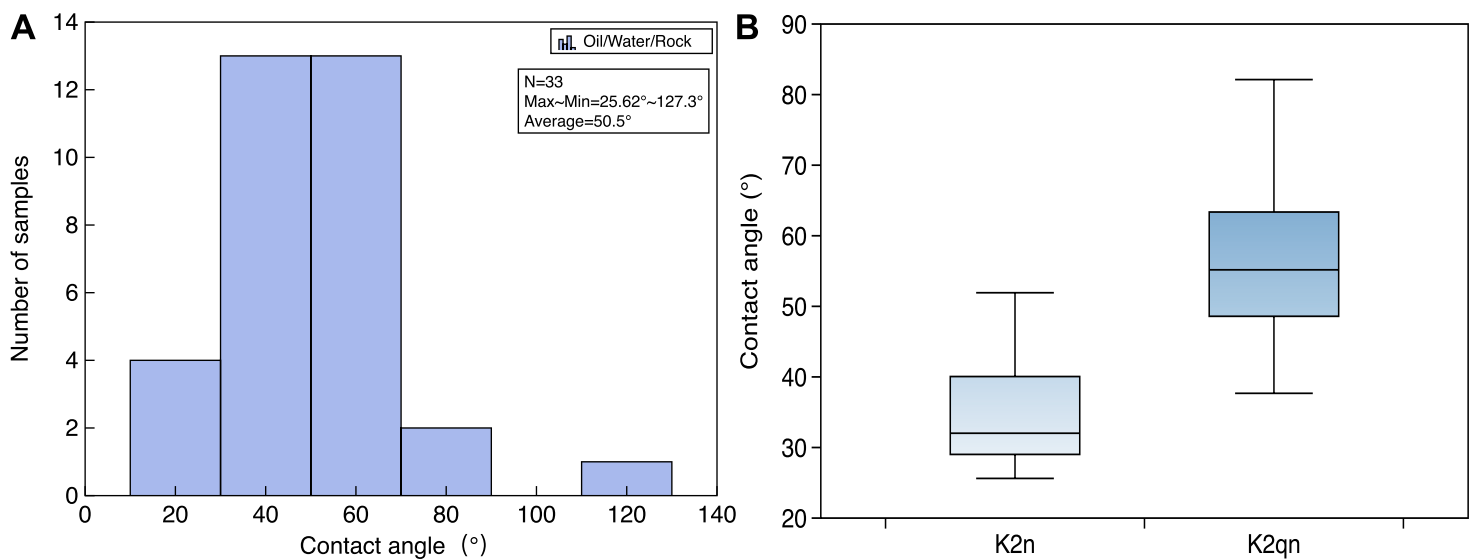

FIGURE 7 | (A) Wettability characteristics of the all shale oil reservoir samples, (B) Wettability characteristics of samples from the Qingshankou and Nengjiang Formations.

TABLE 1 | Samples of different lithofacies for contact angle and liquid-liquid extraction experiments.

\begin{tabular}{|c|c|c|c|c|c|}
\hline Lithofacies & $\begin{array}{l}\text { Number of } \\
\text { samples }\end{array}$ & $\begin{array}{l}\text { TOC } \\
(\%)\end{array}$ & $\begin{array}{c}\text { Siliceous minerals } \\
(\%)\end{array}$ & $\begin{array}{c}\text { Carbonatite minerals } \\
\qquad(\%)\end{array}$ & $\begin{array}{c}\text { Clay minerals } \\
(\%)\end{array}$ \\
\hline Low organic matter silica-rich massive shale & 41 & 0.64 & 76.9 & 2.5 & 20.1 \\
\hline Low organic matter laminated silica-rich shale & 91 & 0.64 & 86.5 & 0.0 & 13.5 \\
\hline Low organic matter bedded silica-rich shale & 80 & 0.97 & 81.6 & 0.8 & 17.6 \\
\hline High organic matter laminated siliceous shale & 49 & 2.15 & 51.8 & 1.7 & 37.5 \\
\hline High organic matter massive siliceous shale & 14 & 2.88 & 48.7 & 10.8 & 36.8 \\
\hline High organic matter massive clay shale & 94 & 4.33 & 18.1 & 1.9 & 80.0 \\
\hline
\end{tabular}
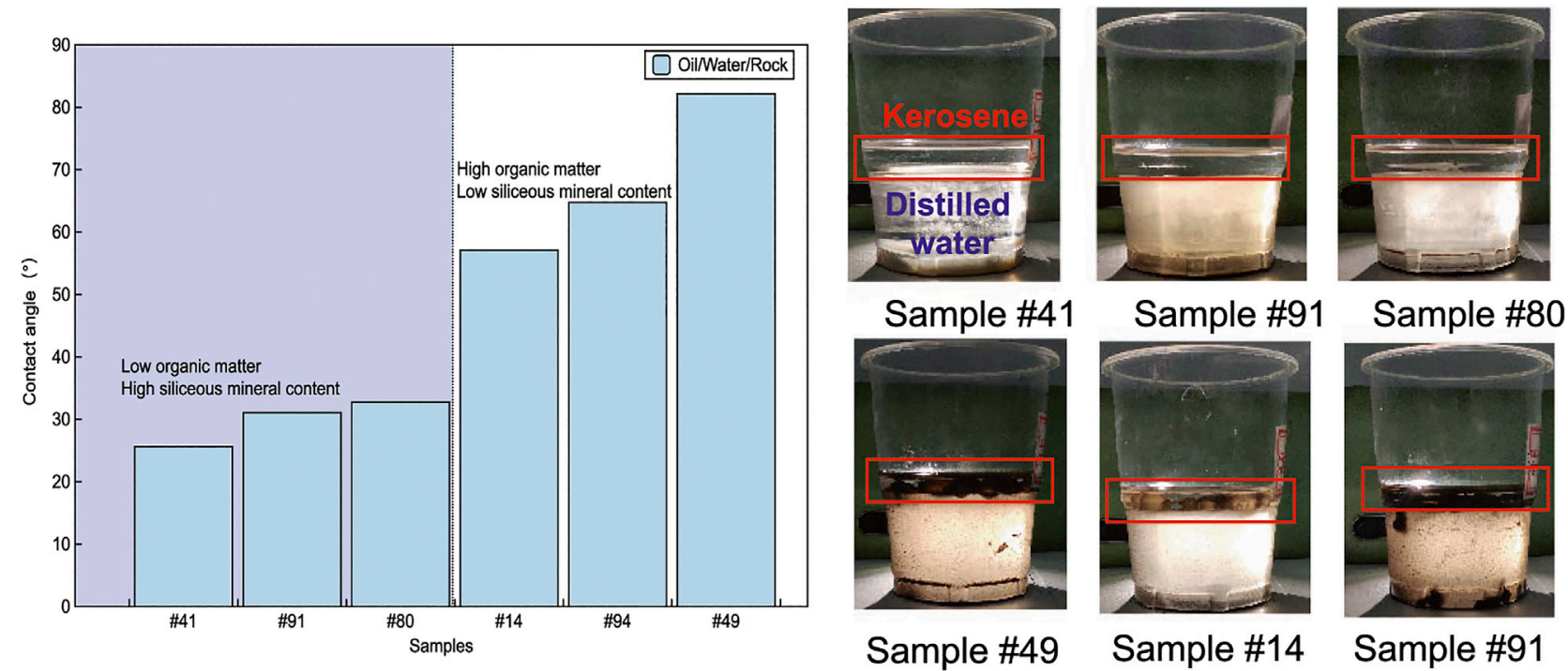

FIGURE 8 | Wettability of different lithofacies. Samples 41, 91, and 80 have high organic matter content and low siliceous mineral content; 14,94 , and 49 are the contrary. 

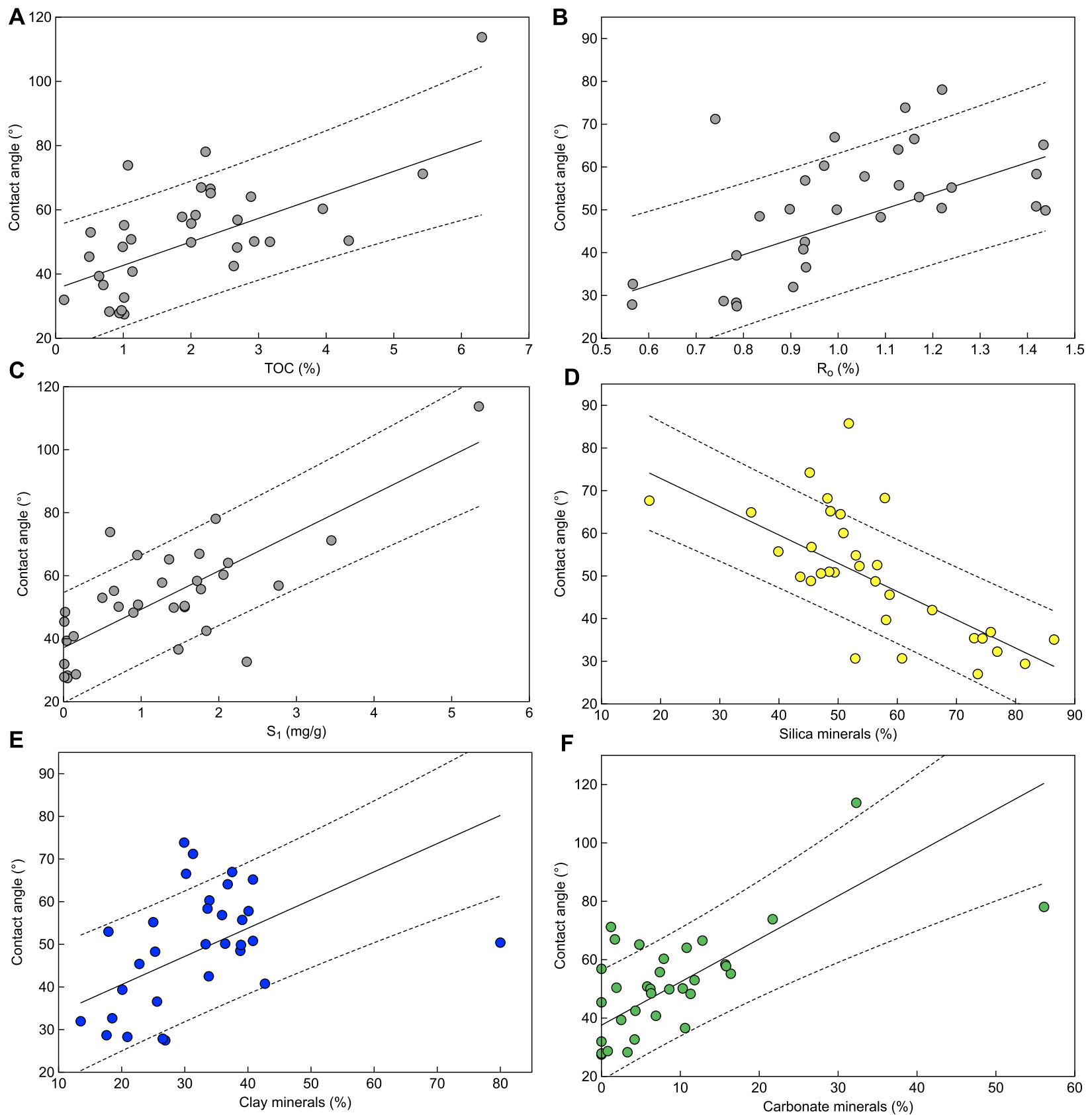

FIGURE 9 | Correlation between wettability and material composition of shale. (A) TOC, (B) $S_{1}$, (C) $R_{0}$, (D) Siliceous minerals, (E) Carbonate minerals, (F) Clay minerals.

Siddiqui (2018) proposed Eq. 1 to achieve the conversion of "gas-water-rock" contact angles on shale surfaces to "oil-waterrock" contact angles.

$$
\theta_{o-w}=\cos ^{-1}\left(\frac{\gamma_{o-g} \cos _{o-g}-\gamma_{w-g} \cos \theta_{w-g}}{\gamma_{o-w}}\right)
$$

Where oil surface tension $\gamma_{o-g}, \mathrm{mN} / \mathrm{m}$; water surface tension $\gamma_{w-g}, \mathrm{mN} / \mathrm{m}$; oil-water interfacial tension $\gamma_{o-w}, \mathrm{mN} / \mathrm{m}$; "gas-oil-rock" contact angle $\theta_{o-g} ;$ "gas-water-rock" contact angle $\theta_{w-g}$; "oil-water-rock" contact angle $\theta_{o-w}$.

To verify the accuracy of Eq. 1, 10 samples were selected to carry out "gas-oil-rock", "gas-water-rock" and "oil-waterrock" contact angle experiments. The water samples were ionized water, and the oil samples were kerosene. The parameters and the calculated "oil-water-rock" contact angles are shown in Supplementary Table S3. 


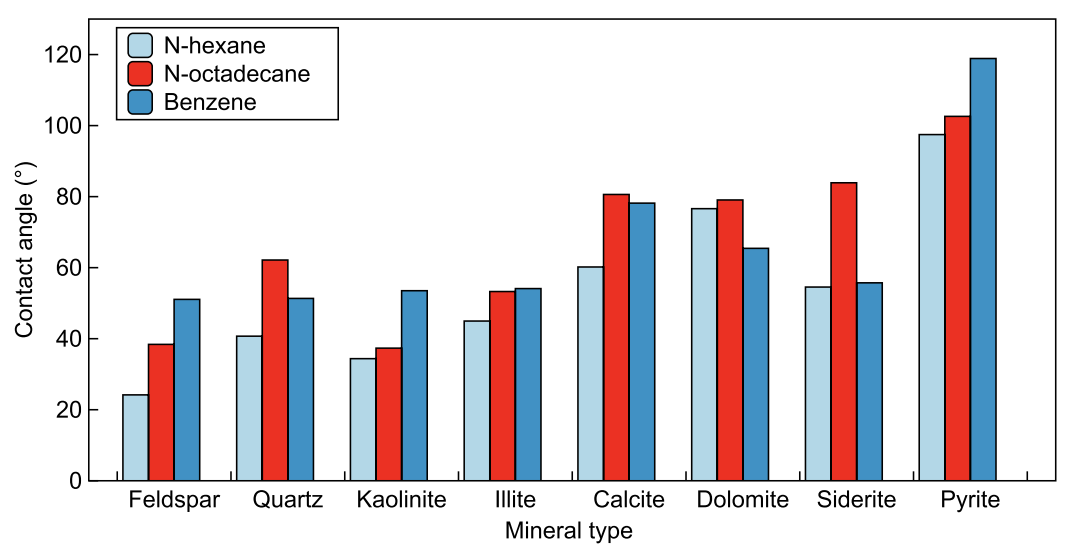

FIGURE 10 | Wettability of fresh minerals. Fresh minerals are the main components of shale.
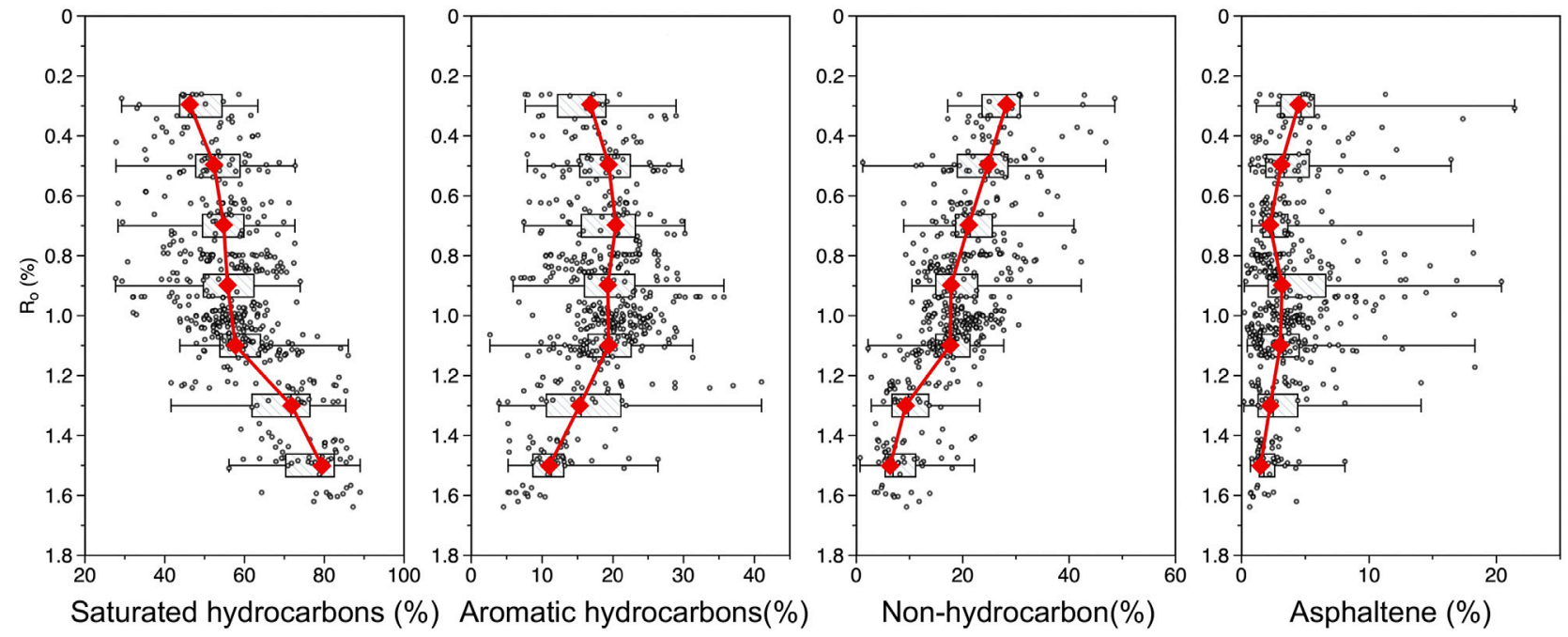

FIGURE 11 | Characteristics of shale oil components in the target area with maturity.

The excellent correlation between measured and calculated contact angles (Supplementary Figure S2) demonstrates that this formula can be applied to calculate the "oil-water-rock" contact angle for shales. However, the measured values are always less than the theoretical oil-water contact angle, which means that the measured results are more hydrophilic than the theoretical ones, probably because the rock sheet is preferentially wholly immersed in water and a film is formed on the surface, which increases the hydrophilicity of the rock sheet.

\section{High Temperature and Pressure Contact Angle Experiments}

A high temperature and pressure contact angle experiment was carried out to study temperature and pressure on the wettability of "oil-water-rock" (Supplementary Figure S3). The instrument includes a high temperature and pressure chamber, water injection pump, oil injection pump (or gas injection pump), high precision camera, and computer processing.

\section{RESULT AND DISCUSSION}

\section{Wettability Characteristics of Shales} Comparison of Different Formations

The "oil-water-rock" contact angle $(\boldsymbol{\theta})$ results for the samples are shown in Figure 10. The samples are almost all hydrophilic, with $\boldsymbol{\theta}$ overwhelmingly in the range of $25-80^{\circ}$. The samples can be further classified according to the differences in water-wetting properties: strong water-wetting $\left(\theta<30^{\circ}\right)$, medium waterwetting $\left(30^{\circ}<\boldsymbol{\theta}<60^{\circ}\right)$ and weak water-wetting $\left(60^{\circ}<\boldsymbol{\theta}<90^{\circ}\right)$. The majority of samples were medium water-wet, with fewer samples being strong or weak water-wet. However, sample 35 is 

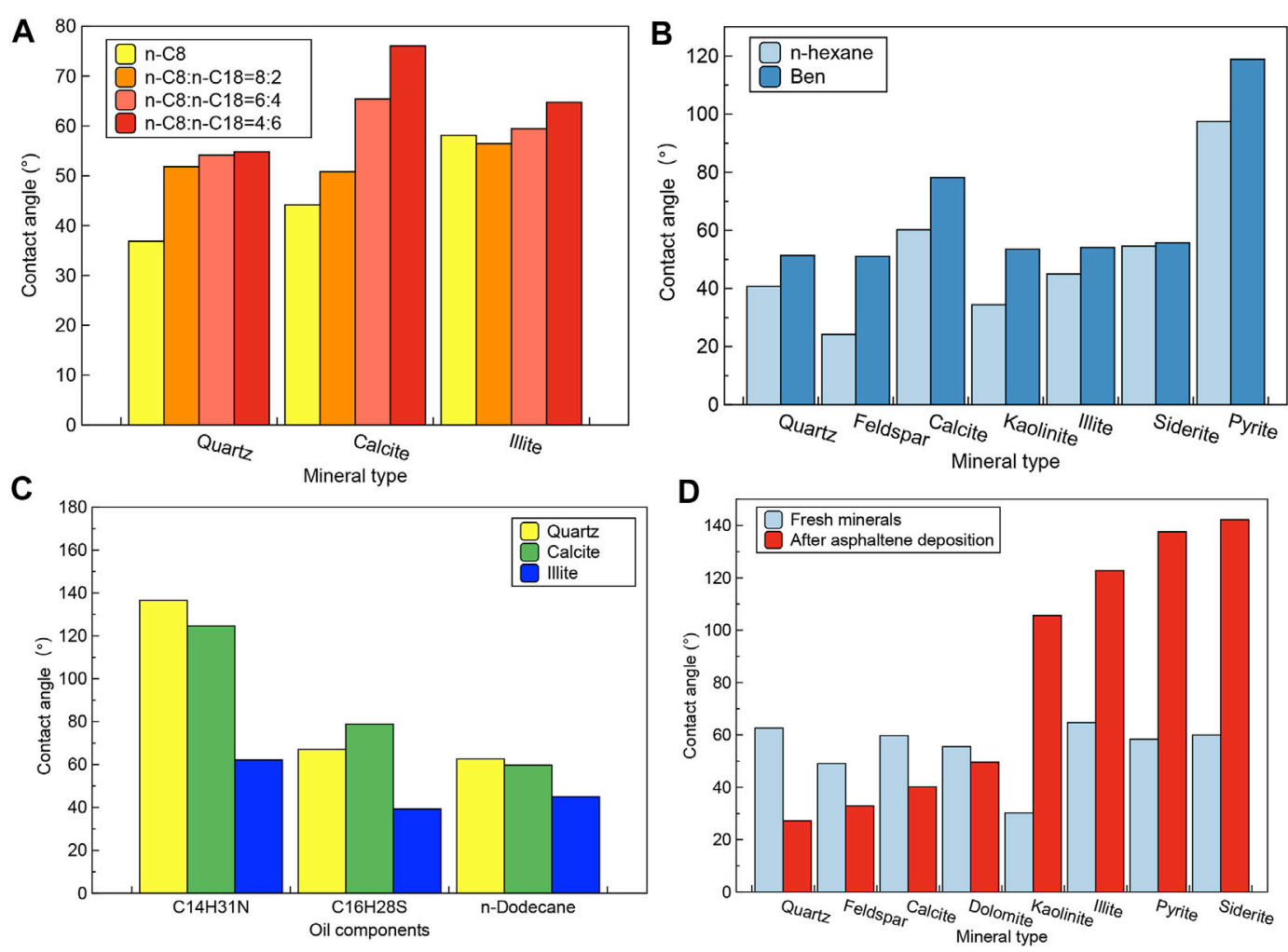

FIGURE 12 | (A) Effect of heavy hydrocarbon content on wettability, (B) Effect of aromatic content on wettability, (C) Effect of non-hydrocarbon content on wettability, (D) Effect of asphaltene deposition on wettability.

oil-wet $\left(\theta=90.15^{\circ}\right)$ owing to the high TOC $(6.3 \mathrm{wt} \%)$ and carbonate minerals content $(32.3 \%)$.

Figure 7 shows that the water-wetness of the Nengjiang is significantly better than that of the Qingshankou. The two have a similar mineral composition, so minerals are not the cause of the difference in wettability. The TOC of the Qingshankou is slightly higher than that of the Nengjiang, but the maturity of organic matter is significantly higher than that of the Nengjiang. The Qingshankou Formation has completed a large amount of hydrocarbon expulsion $\left(S_{1}\right.$ and $S_{2}$ are high), and the adsorption of polar oil components renders wettability towards oil wetting. The low maturity Nengjiang has not yet undergone significant hydrocarbon expulsion $\left(S_{1}\right.$ and $S_{2}$ are low), and the reservoir is in primitive water-wetting. Maturity is the reason for the difference in wettability between the Qingshankou and Nengjiang.

\section{Comparison of Different Lithofacies}

Table 1 illustrates the major lithofacies in the target area. The samples can be divided into two groups according to their TOC and mineral content. The first group, 41, 91, and 80, are characterized by low TOC $(<1 \mathrm{wt} \%)$, low clay mineral content $(\leq 20.1 \%)$, and high siliceous mineral content $(\geq 76.9 \%)$. The second group is 49,14 , and 94 , which are characterized by high TOC $(>2 \%)$ and higher clay mineral $(\geq 36.8 \%)$ content.

The results of the "oil -water-rock" contact angle measurements for the rocks are shown in Figure 8. The first group of rock samples $(41,91$, and 80$)$ have contact angles in the range of $26^{\circ}-31^{\circ}$, which are strongly hydrophilic. The second group of rock samples $(14,94$, and 49$)$ have contact angles in the range of $58^{\circ}-80^{\circ}$, respectively, and are weak water-wetness, presumably related to their high TOC and clay mineral content.

The results of the LLE are consistent with the CA (Figure 8). The first group of rock particles is mainly distributed in the water layer, while only a few particles are distributed in the oil-water interface and kerogen. This indicates that all rock particles in the first group are hydrophilic. The second group is partly suspended at the kerosene, partly suspended in DI water. This shows that they are both hydrophilic and oleophilic. The number of oleophilic particles is related to the TOC.

\section{Factors Influencing Shale Wettability Organic Matter and Mineral Composition Characteristics}

The relationship between contact angle and organic characteristics is analyzed in Figures 9A-C. TOC, $S_{1}$, and $\mathrm{R}_{\mathrm{o}}$ have a positive correlation with oil-wet. Recently, various studies have shown the lipophilic of organic matter (Siddiqui et al., 2018). This means that the higher the organic matter abundance the more oil-wet the sample is, which is consistent with the conclusions obtained from Figure 8. $S_{1}$ is related to the oil content. As the oil content increases, the surface gradually shifts from water-wet to oil-wet. Previous 

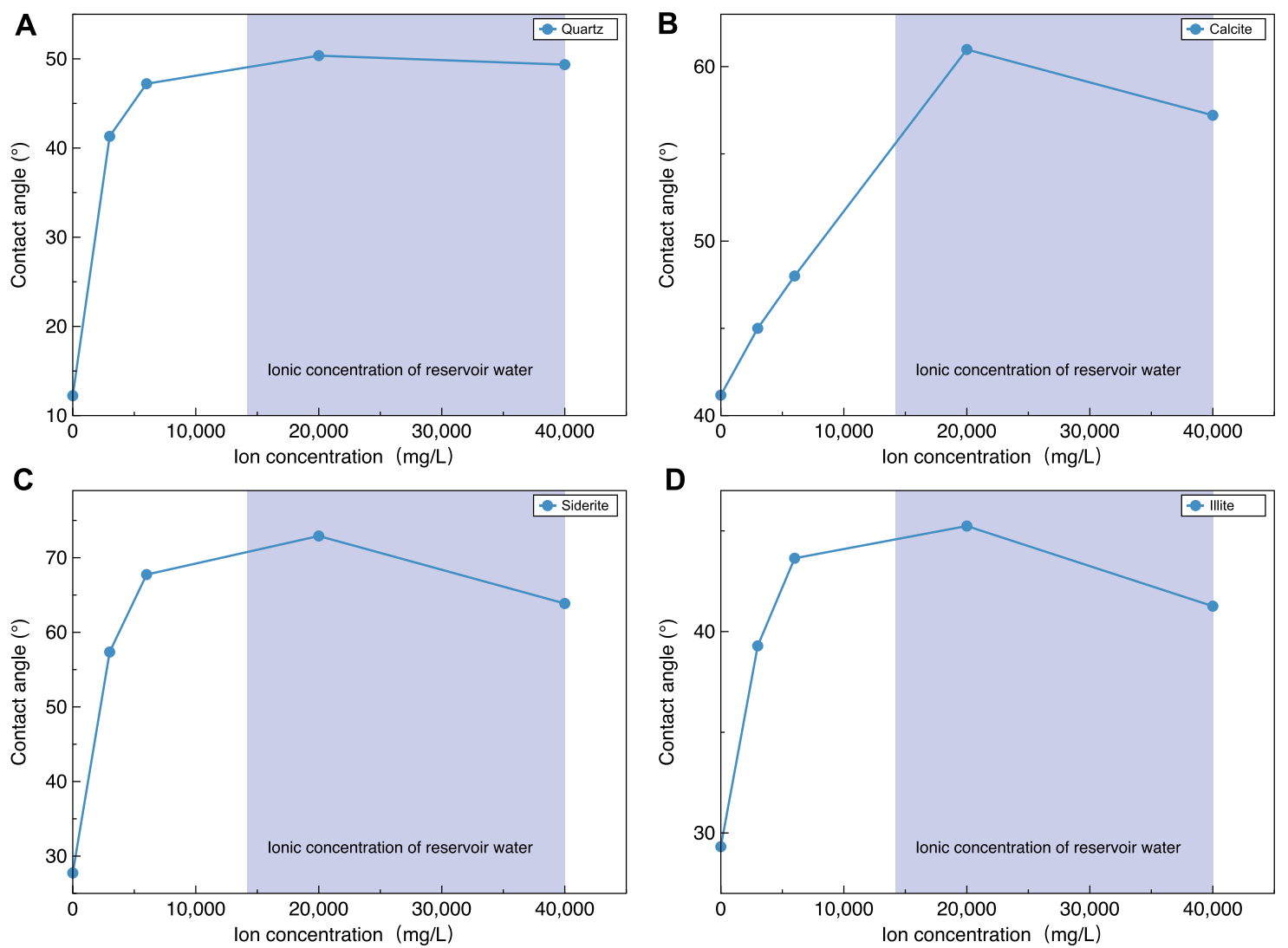

FIGURE 13 | Variation of wettability with $\mathrm{CaCl}_{2}$ concentration. (A) quartz, (B) calcite, (C) siderite, (D) illite.

molecular dynamics results (Jagadisan et al., 2019) have shown that low maturity organic matter is more hydrophilic. In addition, the low maturity means that the oil has not yet been generated in large quantities and it is difficult to shift the surface to oil-wetness.

The relationship between contact angle and mineral composition characteristics is analyzed in Figures 9D-F. Siliceous minerals are positively correlated with water-wet. However, carbonate and clay minerals are negatively correlated with water-wet. The strong waterwet of siliceous minerals and the weak water-wet of carbonate minerals have been confirmed, but there is no agreed understanding of the wettability of clay minerals. Therefore, it was necessary to carry out wettability experiments with a single pure mineral to verify the conclusions of Figures 9D-F.

Figure 10 compares the affinity of different fresh minerals for hydrocarbons (saturated and aromatic hydrocarbons). Eight minerals exhibit hydrophilic properties $\left(\theta<90^{\circ}\right)$. The order of affinity of minerals to hydrocarbons is carbonate minerals $>$ clay minerals $>$ siliceous minerals. Siliceous minerals exhibit strong water-wetting, and calcareous minerals exhibit weak water-wetting. The shale is essentially medium water-wetting. Then, an increase in siliceous/ calcareous minerals will shift the shale towards strong/weak waterwetting. This is consistent with the conclusions obtained in Figure 9. However, the wettability of the clay minerals obtained from Figures 9F, 10 is inconsistent. Considering that no experiments were carried out to remove oil from the cores after the samples were extracted in situ, a certain amount of colloidal asphaltene is deposited on the surface of the clay minerals. It is the deposition of colloidal asphaltene that reverses the wettability, giving a seemingly unreasonable negative correlation between clay mineral content and water-wetting.

\section{Oil Components}

The physicochemical properties of shale oil are related to its composition (saturated hydrocarbons, aromatic hydrocarbons, non-hydrocarbons, asphaltenes), which varies with the maturity of the organic matter. Figure 11 shows the composition of shale oil for different maturity of organic matter. The results show that as the depth of burial increases, i.e., the maturity of the organic matter (Ro) increases, the saturated hydrocarbon fraction tends to grow, the aromatic and non-hydrocarbon fractions tend to decrease, the asphaltene does not change much, and the ratio of saturated to aromatic hydrocarbons tends to increase.

High carbon number alkanes show more affinity to mineral surfaces than low carbon number alkanes (Figure 12A). Since $\mathrm{n}$-octadecane is a solid at room temperature, solutions of different ratios of n-octadecane and n-octadecane have been configured to represent high carbon number alkanes. Figure 12A shows that as the $n-C_{18} / n-C_{8}$ increases, the contact angle increases and the affinity of the mineral to the oil is stronger.

For the same carbon number, aromatic hydrocarbons have a stronger affinity for minerals than alkanes (Figure 12B). The proportion of aromatics decreases as the depth of formation 


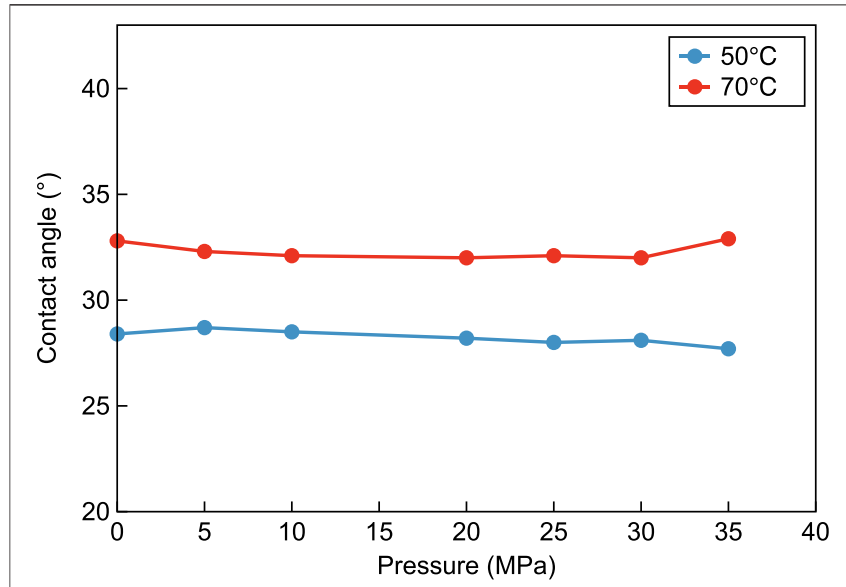

FIGURE 14 | Effect of temperature and pressure on wettability. The system is "quartz - kerosene- distilled water".

increases, this reduces the affinity of the oil to the reservoir surface.

Polar oil components have a greater affinity for minerals than non-polar oil components (Figure 12C). The affinity of oil components for minerals is nitrogenous compounds > sulfurous compounds $>$ alkanes. Most of the mineral surfaces that exist in nature are polar, so it is not difficult to understand this. It is the extremely strong affinity of polar compounds that renders the surface to oil-wetness. The proportion of nonhydrocarbons decreases as the depth of formation increases, this reduces the affinity of the oil to the reservoir surface.

Asphaltene deposition converts the surface to lipophilic, especially for clay minerals (Figure 12D). The wettability of fresh minerals is compared with that of minerals immersed in crude oil for $48 \mathrm{~h}$. The wettability of the clay minerals undergoes a dramatic shift from strongly water-wet to oilwet. The water-wetness of the siliceous and carbonate minerals increased instead, probably due to the short immersion time.

\section{Brine Salinity}

Considering that $\mathrm{CaCl}_{2}$ is the main additive in fracturing fluids, this study investigates the change in wettability of different salinities of $\mathrm{CaCl}_{2}$ (Figure 13). As the brine salinity increases, the contact angle tends to rise and then fall for all four mineral types. Low salinity flooding may be the way to enhance shale oil recovery.

\section{Temperature and Pressure Conditions}

The experimental results are shown in Figure 14. When the temperature is $50^{\circ} \mathrm{C}$ or $70^{\circ} \mathrm{C}$, the contact angle does not change significantly as the pressure increases. At the same ambient pressure, as the temperature increases (by $20^{\circ} \mathrm{C}$ ), the contact angle value becomes larger (by approximately $5^{\circ}$ ) and the oil wettability increases. It is worth noting that an increase in pressure can lead to a rupture of the water film on the reservoir surface and thus a decrease in water wettability.

\section{CONCLUSION}

This manuscript characterizes the wettability of the Qingshankou and Nengjiang formations in the northern Songliao Basin by using contact angle and liquid-liquid extraction experiments. Fresh minerals, a component of oil, and different temperature/pressure conditions were set up to investigate the factors influencing the wettability of the shale oil reservoirs.

1) Low organic matter maturity is the main factor for the Nenjiang Formation being more hydrophilic than the Qingshankou Formation.

2) TOC, $S_{1}$, and $R_{o}$ of shale have a positive correlation with oilwet. Siliceous minerals are positively correlated with waterwet. Carbonate and clay minerals are negatively correlated with water-wet.

3) The mineralogical composition of the shale, the composition of the oil, the characteristics of the aqueous media, the asphaltene deposits on the surface, temperature, and pressure all have an impact on wettability. The affinity of minerals for hydrocarbons is iron minerals $>$ carbonate minerals $>$ clay minerals $>$ siliceous minerals. Minerals are more hydrophilic at low salinity conditions. The deposition of non-hydrocarbons and asphaltenes renders the surface oleophilic. Increasing temperatures will reduce the hydrophilicity of the "oil-waterrock”.(Lu et al., 2012; Wang et al., 2016; Zhang et al., 2018).

\section{DATA AVAILABILITY STATEMENT}

The original contributions presented in the study are included in the article/Supplementary Material, further inquiries can be directed to the corresponding author.

\section{AUTHOR CONTRIBUTIONS}

HX designed the project and wrote the main manuscript. ZD and ST help to draw the figures and to draft the manuscript. SL defined the statement of the problem. CA helped to discuss the problems and revise the manuscript. YZ helped to discuss the main idea and helped to draft the manuscript. BL help to calculate the data and draw the figures. XX helped to revise the figures. All authors reviewed the manuscript.

\section{FUNDING}

This study was partly funded by the National Natural Science Foundation of China (42072160, 41922015).

\section{SUPPLEMENTARY MATERIAL}

The Supplementary Material for this article can be found online at: https://www.frontiersin.org/articles/10.3389/feart.2021.736938/ full\#supplementary-material 


\section{REFERENCES}

Agbalaka, C. C., Dandekar, A. Y., Patil, S. L., Khataniar, S., and Hemsath, J. R. (2009). Coreflooding Studies to Evaluate the Impact of Salinity and Wettability on Oil Recovery Efficiency. Transp Porous Med. 76 (1), 77-94. doi:10.1007/ s11242-008-9235-7

Alvarez, J. O., and Schechter, D. S. (2016a). Application of Wettability Alteration in the Exploitation of Unconventional Liquid Resources. Pet. Exploration Dev. 43 (5), 832-840. doi:10.1016/S1876-3804(16)30099-4

Alvarez, J. O., and Schechter, D. S. (2016b). Application of Wettability Alteration in the Exploitation of Unconventional Liquid Resources. Pet. Exploration Dev. 43 (5), 832-840. doi:10.1016/S1876-3804(16)30099-4

Athy, L. F. (1930). Compaction and Oil Migration. AAPG Bull. 14, 25-35. doi:10.1306/3d93289f-16b1-11d7-8645000102c1865d

Bechtel, A., Jia, J., Strobl, S. A. I., Sachsenhofer, R. F., Liu, Z., Gratzer, R., et al. (2012). Palaeoenvironmental Conditions during Deposition of the Upper Cretaceous Oil Shale Sequences in the Songliao Basin (NE China): Implications from Geochemical Analysis. Org. Geochem. 46, 76-95. doi:10.1016/j.orggeochem.2012.02.003

Begum, M., Yassin, M. R., Dehghanpour, H., and Of Alberta, U. (2019). Effect of Kerogen Maturity on Organic Shale Wettability: A Duvernay Case Study. Mar. Pet. Geology. 110, 483-496. doi:10.1016/j.marpetgeo.2019.07.012

Berg, S., Cense, A. W., Jansen, E., and Bakker, K. (2010). Direct Experimental Evidence of Wettability Modification by Low Salinity. Petrophysics-The SPWLA J. Formation Eval. Reservoir Description 51 (5), 314-322. doi:10.1016/ j.petrol.2010.08.016

Borysenko, A., Clennell, B., Sedev, R., Burgar, I., Ralston, J., Raven, M., et al. (2009). Experimental Investigations of the Wettability of Clays and Shales. J. Geophys. Res. 114. doi:10.1029/2008JB005928

Buckley, J. S. (2001). Effective Wettability of Minerals Exposed to Crude Oil. Curr. Opin. Colloid Interf. Sci. 6, 191-196. doi:10.1016/s1359-0294(01)00083-8

Chalmers, G. R., Bustin, R. M., Power, I. M., Bustin, R. M., and Power, I. M. (2012). Characterization of Gas Shale Pore Systems by Porosimetry, Pycnometry, Surface Area, and Field Emission Scanning Electron Microscopy/ transmission Electron Microscopy Image Analyses: Examples from the Barnett, Woodford, Haynesville, Marcellus, and Doig Units. Bulletin 96 (6), 1099-1119. doi:10.1306/10171111052

Chalmers, G. R., Bustin, R. M., and Power, I. M. (2012). Characterization of Gas Shale Pore Systems by Porosimetry, Pycnometry, Surface Area, and Field Emission Scanning Electron Microscopy/transmission Electron Microscopy Image Analyses: Examples from the Barnett, Woodford, Haynesville, Marcellus, and Doig Units. Bulletin 96, 1099-1119. doi:10.1306/10171111052

Chen, J., Hirasaki, G. J., and Flaum, M. (2006). NMR Wettability Indices: Effect of OBM on Wettability and NMR Responses. J. Pet. Sci. Eng. 52, 161-171. doi:10.1016/j.petrol.2006.03.007

Drummond, C., and Israelachvili, J. (2004). Fundamental Studies of Crude Oil-Surface Water Interactions and its Relationship to Reservoir Wettability. J. Petrol. Sci. Eng. 45 (5), 61-81. doi:10.1016/j.petrol.2004.04.007

Ehrlich, R., Hasiba, H. H., and Raimondi, P. (1974). Alkaline Waterflooding for Wettability Alteration-Evaluating a Potential Field Application. J. Pet. Tech. 26 (3), 1335-1343. doi:10.2118/4905-pa

He, T., Li, W., Lu, S., Pan, W., Ying, J., Zhu, P., et al. (2022). Mechanism and Geological Significance of Anomalous Negative $\delta 13$ Ckerogen in the Lower Cambrian, NW Tarim Basin, China. J. Pet. Sci. Eng. 208, 109384. doi:10.1016/ j.petrol.2021.109384

He, T., Lu, S., Li, W., Tan, Z., and Zhang, X. (2018). Effect of Salinity on Source Rock Formation and its Control on the Oil Content in Shales in the Hetaoyuan Formation from the Biyang Depression, Nanxiang Basin, Central China. Energy Fuels 32 (6), 6698-6707. doi:10.1021/acs.energyfuels.8b01075

Hideo Nakae, H., Ryuichi Inui, R., Yosuke Hirata, Y., and Hiroyuki Saito, H. (1998). Effects of Surface Roughness on Wettability. Acta Materialia 46 (7), 2313-2318. doi:10.1016/s1359-6454(98)80012-8

Hou, D., Li, M., and Huang, Q. (2000). Marine Transgressional Events in the Gigantic Freshwater lake Songliao: Paleontological and Geochemical Evidence. Org. Geochem. 31 (7-8), 763-768. doi:10.1016/S0146-6380(00)00065-6

Hoxha, B. B., Sullivan, G., Van Oort, E., Daigle, H., and Schindler, C. (2016). "Determining the Zeta Potential of Intact Shales via Electrophoresis," in SPE
Europec featured at 78th EAGE Conference and Exhibition.. June 2016, Vinna,Austria, doi:10.2118/180097-ms

Jagadisan, A., and Heidari, Z. (2019). "Demystifying Wettability Alteration in Kerogen as a Function of its Geochemistry and Reservoir Temperature and Pressure Using Molecular Dynamics Simulations," in SPE Annual Technical Conference and Exhibition.. Sep 30 2019, Calgary, AB Canada, doi:10.2118/ 195863-ms

Jia, J., Liu, Z., Bechtel, A., Strobl, S. A. I., and Sun, P. (2013). Tectonic and Climate Control of Oil Shale Deposition in the Upper Cretaceous Qingshankou Formation (Songliao Basin, NE China). Int. J. Earth Sci. (Geol Rundsch) 102 (6), 1717-1734. doi:10.1007/s00531-013-0903-7

Jia, L., Li, K., Shi, X., Zhao, L., and Linghu, J. (2021). Application of Gas Wettability Alteration to Improve Methane Drainage Performance: A Case Study. Int J. Mining Sci. Tech.. 31 (4):621-629 doi:10.1016/j.ijmst.2021.04.002

Kumar, K., Dao, E., and Mohanty, K. K. (2005). AFM Study of mineral Wettability with Reservoir Oils. J. Colloid Interf. Sci. 289, 206-217. doi:10.1016/ j.jcis.2005.03.030

Li, C., Singh, H., and Cai, J. (2019). Spontaneous Imbibition in Shale: A Review of Recent Advances. Capillarity 2, 17-32. doi:10.26804/capi.2019.02.01

Li, J., Li, X., Wu, K., Feng, D., Zhang, T., and Zhang, Y. (2017). Thickness and Stability of Water Film Confined inside Nanoslits and Nanocapillaries of Shale and clay. Int. J. Coal Geology. 179, 253-268. doi:10.1016/j.coal.2017.06.008

Li, W., Lu, S., Li, J., Wei, Y., Feng, W., Zhang, P., et al. (2021). Geochemical Modeling of Carbon Isotope Fractionation during Methane Transport in Tight Sedimentary Rocks. Chem. Geology. 566, 120033. doi:10.1016/ j.chemgeo.2020.120033

Liu, B., Bai, L., Chi, Y., Jia, R., Fu, X., and Yang, L. (2019). Geochemical Characterization and Quantitative Evaluation of Shale Oil Reservoir by Two-Dimensional Nuclear Magnetic Resonance and Quantitative Grain Fluorescence on Extract: A Case Study from the Qingshankou Formation in Southern Songliao Basin, Northeast China. Mar. Pet. Geology. 109, 561-573. doi:10.1016/j.marpetgeo.2019.06.046

Liu, B., Shi, J., Fu, X., Lyu, Y., Sun, X., Gong, L., et al. (2018). Petrological Characteristics and Shale Oil Enrichment of Lacustrine fine-grained Sedimentary System: A Case Study of Organic-Rich Shale in First Member of Cretaceous Qingshankou Formation in Gulong Sag, Songliao Basin, NE China. Pet. Exploration Dev. 45 (5), 884-894. doi:10.1016/S1876-3804(18) 30091-0

Liu, B., Sun, J., Zhang, Y., He, J., Fu, X., Yang, L., et al. (2021). Reservoir Space and Enrichment Model of Shale Oil in the First Member of Cretaceous Qingshankou Formation in the Changling Sag, Southern Songliao Basin, NE China. Pet. Exploration Dev. 48 (3), 608-624. doi:10.1016/S1876-3804(21) 60049-6

Loucks, R. G., and Reed, R. M. (2014). Scanning-electron-microscope Petrographic Evidence for Distinguishing Organic-Matter Pores Associated with Depositional Organic Matter versus Migrated Organic Matter in Mudrock [J].

Lu, S., Huang, W., Chen, F., Li, J., Wang, M., Xue, H., et al. (2012). Classification and Evaluation Criteria of Shale Oil and Gas Resources: Discussion and Application. Pet. exploration Dev. 39 (2), 268-276. doi:10.1016/S18763804(12)60042-1

Lu, Y., Zeng, L., Sari, A., Chen, Y., Jin, Y., and Xie, Q. (2019). Wetting Behavior of Shale Rocks and its Relationship to Oil Composition. Energy Fuels 33, 12270-12277. doi:10.1021/acs.energyfuels.9b02935

Marsden, S. S. (1965). Wettability-Its Measurement and Application to Waterflooding. J. Jpn. Assoc. Petrol. Technol. 30 (1), 1-10. doi:10.3720/japt.30.1

Pan, B., Yin, X., and Iglauer, S. (2020). A Review on clay Wettability: From Experimental Investigations to Molecular Dynamics Simulations. Adv. Colloid Interf. Sci. 285 (1), 102266. doi:10.1016/j.cis.2020.102266

Roshan, H., Al-Yaseri, A. Z., Sarmadivaleh, M., and Iglauer, S. (2016). On Wettability of Shale Rocks. J. Colloid Interf. Sci. 475, 104-111. doi:10.1016/ j.jcis.2016.04.041

Siddiqui, M. A. Q., Ali, S., Fei, H., and Roshan, H. (2018). Current Understanding of Shale Wettability: A Review on Contact Angle Measurements. Earth-Science Rev. 181, 1-11. doi:10.1016/j.earscirev.2018.04.002

Song, M., Liu, H., Wang, Y., and Liu, Y. (2020). Enrichment Rules and Exploration Practices of Paleogene Shale Oil in Jiyang Depression, Bohai Bay Basin, China. Pet. Exploration Dev. 47 (2), 242-253. doi:10.1016/ S1876-3804(20)60043-X 
Wang, Y., Wang, X., Song, G., Liu, H., Zhu, D., Zhu, D., et al. (2016). Genetic Connection between Mud Shale Lithofacies and Shale Oil Enrichment in Jiyang Depression, Bohai Bay Basin. Pet. Exploration Dev. 43 (5), 759-768. doi:10.1016/s1876-3804(16)30091-x

Xue, H., Dong, Z., Chen, X., Tian, S., Lu, S., and Lu, S. (2021). Simulation of Oil-Water Rock Wettability of Different Constituent Alkanes on Kaolinite Surfaces at the Nanometer Scale. j nanosci nanotechnol 21, 225-233. doi:10.1166/jnn.2021.18727

Yang, R., Hu, Q., He, S., Hao, F., Guo, X., Yi, J., et al. (2019). Wettability and Connectivity of Overmature Shales in the Fuling Gas Field, Sichuan Basin (China). Bulletin 103 (3), 653-689. doi:10.1016/S1876-3804(16)30091-X

Yu, L., and Wardlaw, N. C. (1986). The Influence of Wettability and Critical PoreThroat Size Ratio on Snap-Off. J. Colloid Interf. Sci. 109 (2), 461-472. doi:10.1016/0021-9797(86)90324-3

Zhang, T., Li, X., Shi, J., Sun, Z., Yin, Y., Wu, K., et al. (2018). An Apparent Liquid Permeability Model of Dual-Wettability Nanoporous media: A Case Study of Shale. Chem. Eng. Sci. 187, 280-291. doi:10.1016/j.ces.2018.05.016

Zhang, Y., Zeng, J., Qiao, J., Feng, X., and Dong, Y. (2018). Investigating the Effect of the Temperature and Pressure on Wettability in Crude Oil-Brine-Rock Systems. Energy Fuels 32 (9), 9010-9019. doi:10.1021/acs.energyfuels.8b01404
Conflict of Interest: The authors declare that the research was conducted in the absence of any commercial or financial relationships that could be construed as a potential conflict of interest.

The handling Editor declared a past co-authorship with the authors (ST, SL).

Publisher's Note: All claims expressed in this article are solely those of the authors and do not necessarily represent those of their affiliated organizations, or those of the publisher, the editors and the reviewers. Any product that may be evaluated in this article, or claim that may be made by its manufacturer, is not guaranteed or endorsed by the publisher.

Copyright (C) 2021 Xue, Dong, Tian, Lu, An, Zhou, Li and Xin. This is an open-access article distributed under the terms of the Creative Commons Attribution License (CC $B Y)$. The use, distribution or reproduction in other forums is permitted, provided the original author(s) and the copyright owner(s) are credited and that the original publication in this journal is cited, in accordance with accepted academic practice. No use, distribution or reproduction is permitted which does not comply with these terms. 